\title{
Reclaiming our humanity: Believers as sages and performers of the Gospel in the era of the Fourth Industrial Revolution
}

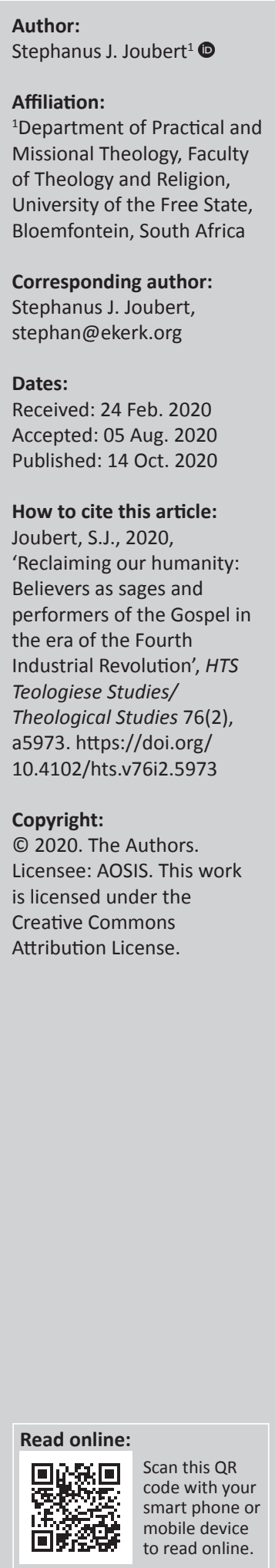

New technologies are emerging across the globe and are influencing our perceptions of the world, our behaviour and our understanding of what it means to be a human being. In particular, Klaus Schwab and others define the advancement of 'cyber-physical systems', coupled with new capacities for both machines and human beings, in terms of 'The Fourth Industrial Revolution'. The South African Parliament placed the Fourth Industrial Revolution on its national agenda. It serves as a new foundation story for the country, one that justifies, explains and facilitates the perceived shifts from previous understandings of reality, and one that currently plays out on an unevenly distributed continuum. To be an effective agent of change and a relevant voice for the voiceless and the powerless in this Fourth Industrial Revolution era, the church must facilitate immersive, yet provocative performances of the Gospels while simultaneously embodying and empowering others with wisdom to traverse this unchartered terrain of technological innovation with insight and discernment. The church's message should be that, to live more godly, we all need to become more human, not post-human or trans-human. We cannot avoid the fact that we are entering an era in which technology will redefine who we are. However, the question is not only what technology can do for us but also what we as change agents should allow technology to do.

Contribution: This article focuses on the role of the Christian church in our era of massive technological innovation. The creative role that faith communities could play in order to ensure a more humane approach to and interaction with various 4IR technologies are addressed. A short investigation is offered of a new 'hermeneutical performance' of the Bible as an immersive text in an interactive 4IR world. In this regard the emphasis on a new 'metanoetic alignment with the mission of Jesus, which is explored in the article, links on to the theological scope of HTS Theological Studies in terms of new theological insights and new vistas for academic investigation.

Keywords: Fourth Industrial Revolution; History; South Africa; Foundation story; Jesus; Gospel; Technology; Sage.

\section{The Fourth Industrial Revolution: A brief history}

Klaus Schwab, executive chairman of the World Economic Forum (WEF), coined the concept 'Fourth Industrial Revolution' (hereinafter, the 4IR). His book, aptly titled The Fourth Revolution (2016), soon impacted on discussions worldwide at universities, development banks, regional economic commissions and governments. Schwab's conversations with his colleague Nicholas Davis regarding the increasing global frenzy regarding technological development and the disruption it causes soon turned into another influential publication (Schwab \& Davis 2018), in which they reflected on how the future of the 4IR would be shaped.

Schwab and Davis are convinced that a global technological revolution is underway - one that not only disrupts the existing ways of calculating, organising, acting and delivering but also blurs the lines between the physical, digital and biological spheres. These technologies are drastically altering the ways in which individuals, groups, companies and governments think, operate and interact. More specifically, technologies such as artificial intelligence, quantum computing, drones, virtual assistants, autonomous vehicles, 3D printing and the Internet of Things are merging with human beings' physical lives in new and unanticipated ways. Schwab believes that,

Note: Special Collection entitled Christianity as Change Agent in the 4th Industrial Revolution World, sub-edited by Erna Oliver (UNISA). 
in terms of scale, scope and complexity, this transformation is unlike anything ever experienced previously by mankind. ${ }^{1}$

The First Industrial Revolution, triggered by the construction of railroads and the invention of the steam engine, spanned from roughly 1760 to 1840 . It marked a transition 'from muscle power to mechanical power, evolving to where today, with the fourth industrial revolution, enhanced cognitive power is augmenting human production' (Schwab 2016:8). The Second Industrial Revolution, which made mass production possible and fostered the advent of electricity, followed at the end of the 19th century and into the first two decades of the 20th century. This era was followed, during the 1960s, by the Third Industrial Revolution. According to Schwab (2016:8), this era is usually called the computer or digital revolution because it was catalyzed by the development of semiconductors, mainframe computing (1960s), personal computing (1970s and 1980s) and the internet (1990s)'. At present, the 4IR is synonymous with the advent of 'cyber-physical systems', involving entirely new capabilities for both people and machines. If Schwab is correct, these vast technological changes are now drastically altering how individuals, companies and governments operate, ultimately leading to a societal transformation similar to previous industrial revolutions. In the words of Davis (2016): ${ }^{2}$

While these capabilities are reliant on the technologies and infrastructure of the Third Industrial Revolution, the Fourth Industrial Revolution represents entirely new ways in which technology becomes embedded within societies and even our human bodies. The complexity of these technologies and their emergent nature makes many aspects of the Fourth Industrial Revolution feel unfamiliar and, to many, threatening. (n.p.)

\section{South African Parliament and the Fourth Industrial Revolution}

Schwab succeeded in removing the topic of fast changing technology out of the silos in which politicians, business leaders and others have been talking about it for far too long as well as in investigating the impact of technology from a systems level rather than from an individual technology level. In particular, he captured the attention of the South African government and State President Cyril Ramaphosa who also attended the annual meetings of the WEF in Davos, Switzerland. ${ }^{3}$ In February 2019, the South African Parliament published an official pamphlet on the 4IR, stating that:

Parliament has taken up the challenge of keeping the Fourth Industrial Revolution on the national agenda ... This is a world where individuals move between digital domains and offline

1.See https://www.weforum.org/agenda/2016/01/the-fourth-industrial-revolutionwhat-it-means-and-how-to-respond/.

2.See https://www.weforum.org/agenda/2016/01/what-is-the-fourth-industrialrevolution/.

3.The theme of the 2016 meeting of the WEF was: 'Mastering the Fourth Industrial Revolution', and the 2019 meeting addressed the topic: 'Globalization 4.0: Shaping a global architecture in the age of The Fourth Industrial Revolution' reality with the uses of connected technology to enable and manage their lives. ${ }^{4}$ (n.p.)

Parliament follows Schwab closely in terms of its understanding of the 4IR as a fusion of technologies, one that is currently blending the lines between the physical, digital and biological spheres. From this perspective, Parliament's agenda, in terms of its support of the 4IR, includes oversight, lawmaking and public participating roles. It is facilitated by means of ongoing roundtable discussions with various government and industry stakeholders as part of its search for effective ways and means to harness the opportunities the 4IR presents in the development of South Africa's future.

Parliament is aware of the risks involved with policy choices in terms of job losses, labour displacement, as well as '... maximising and spreading the positive potentials available for improving the material conditions of the poor and the most vulnerable in our society'. However, Parliament is of the opinion that '...Africa cannot afford to be a spectator as with other industrial revolutions'. Hence, it concludes that there is an urgent need:

$[T]$ o strengthen the role of the legislature to be able to deal with the challenges, enact legislation and also find inclusive ways to maximise the opportunities the Fourth Revolution brings and Parliament must be in the forefront to steer the ship. (n.p.)

\section{The Fourth Industrial Revolution as a new foundation story for South Africa}

With all the hype surrounding the 4IR, the question is whether this is more than simply another highly successful lobbying and policy-influencing concept. At least, it would seem that the 4IR has turned into some kind of a foundation story, one that justifies, explains and facilitates the perceived shifts from previous understandings of reality, as explained by Schwab and the WEF in terms of three previous revolutions. From this perspective, the 4IR functions as the conceptual uniting force as well as the key metaphor for an idealised new reality. From this perspective, people are now challenged to participate in this revolution by means of a different understanding of, and openness to new technologies that are fusing various aspects of the physical, digital and biological worlds. The basic claim of this new foundation narrative is that technology profoundly impacts on all aspects of reality in all countries, societies, economies and industries across the globe, including the church, while challenging all the existing ideas about what it means to be a human being.

Claims to revolutions of this nature are nothing new. Academics, politicians, economists and others have identified shifts in worldviews, symbolic universes and ideologies to paradigms on all levels of society throughout 4.See https://www.parliament.gov.za/storage/app/media/EducationPubs/2019/ january/14-02-2019/4th_Ind_Rev_FINAL_PAMPHLET_1.pdf. 
the ages. In this regard, Thomas Kuhn's (1970) perspectives on paradigm shifts in science might assist us in getting more clarity on the nature of such perceived shifts or revolutions. He argues that progress in science does not take place in a cumulative manner. It is rather a series of peaceful interludes interrupted by the so-called shock waves or 'revolutions', where one conceptual scientific world view or paradigm is replaced in dramatic fashion by another. ${ }^{5}$ In this sense, a particular paradigm provides the methodological and conceptual apparatus for specific groups to formulate theories to solve the problems being investigated. 'At the same time, paradigms also provide the criteria for identifying problems that can be assumed to have solutions' (Kuhn 1970:37).

Not only scientific communities but also large societies and even countries sometimes run into trouble when more and more puzzles cannot be effectively solved within the framework of specific paradigms designed to explain, manage and govern such social systems. In response, role players on various levels of society, such as politicians, economists and academics, will normally devise articulations and ad hoc modifications of their theories, plans and strategies to address the problems and challenges inherent in their societies. However, when role players such as the WEF or the South African Government (in the case of the 4IR) eventually conclude that the existing paradigms (i.e., the previous three revolutions!) have ceased to function adequately in solving the existing challenges, they begin to address this dilemma by reframing the debate on various levels of society in terms of claims to and accompanying descriptions of a new conceptual transformation. Such claims are aimed at both drastically changing the perspectives of target groups and facilitating the replacement of previously accepted explanations of reality. At the same time, they focus on the identification of new challenges, together with the application of new systems, models and analytical tools to help solve them. In short, the aim of such a paradigm shift or revolution is to facilitate a reinterpretation of the existing systems of knowledge and a new world view where people's perceptions of phenomena are completely altered.

Revolutions of the 4IR kind are not necessarily the result of cumulative developments, or a gradual replacement of old paradigms by new ones, but rather the so-called 'Gestalt switches', or as Kuhn (1970:122) calls them 'flashes of intuition, lightning flashes, where one paradigm is replaced in a creative leap by another one which holds out a new promise for success in the solving of problems'. Hence, the eventual choice of a new paradigm is not always 'the result of rational decisions; it is a complex procedure in which historical, psychological and social factors all play an important role' (Joubert 2014:10).

5.According to Kuhn (1970:175) a paradigm refers to the entire constellation of beliefs and techniques shared by the members of a particular scientific community. beliefs and techiques shared by the members of a particular scientific community. At the same time, it also denotes a particular element in this constellation, namely, 'the concrete puzzle-solutions which, employed as models or examples, can replace explicit rules as a basis for the solution of the remaining puzzles of normal science'.

\section{The Fourth Industrial Revolution plays out on a continuum}

It is one thing to lay claim to a revolution of the 4IR kind, but quite another to anchor it in everyday reality. Could the WEF and the South African Government's hopes of job creation and exponential economic growth by means of advanced new technologies actually become a reality? The fact of the matter is that, with roughly 700000 new young people entering South Africa's job market annually, a projected growth rate of $10 \%$ will be required to absorb them into the economy. Surely, this could not be done only through the introduction of a series of 'cyber-physical systems' into the market arena or the facilitation of a number of disruptive technologies that also have the potential to turn into a driver of increased inequality and unemployment as well as increased segregation and social unrest. Or could it? Hence the question: In what sense would the implementation of new technologies associated with the 4IR determine the expected positive outcomes per se? Phrased differently, is there anything inherent in such technologies that would necessarily result in heightened economic growth, job creation or empowerment of the marginalised, as Gillwald 6 rightly asks? Clarity on this question could help shape such changes in more responsive ways that could assist the formation of a new era, one that will improve people's lives and create new opportunities for the millions who are currently excluded from economic and other privileges.

Is a 4IR already underway on ground zero in South Africa? Probably not, but there are early signs of its emergence. ${ }^{7}$ No one would deny that South Africa has experienced a number of seismic shifts over the past decades, ranging from apartheid to post-apartheid, colonialism to post-colonialism, modernism to post-modernism, Christendom to postChristendom and currently from non-liquid modernity to liquid modernity. ${ }^{8}$ The liquefying of a once fixed society, which consisted of a bound set of predictable structures, institutions, norms and values, is one of the defining characteristics of the present South African landscape. At least, reality for many South Africans is no longer only a physical space. A 2019 study by Hootsuite's Global State of Digital found that the typical South African internet user spends $8 \mathrm{~h} 23 \mathrm{~min}$ on the internet daily, compared with $6 \mathrm{~h} 38 \mathrm{~min}$ in the United States of America. South African cellular phone owners also spend a long time on the web daily - an average of $3 \mathrm{~h} 30 \mathrm{~min}$, compared with the global 6.See https://researchictafrica.net/wp/wp-content/uploads/2019/09/Gillwald afrisig2019_4IR.pdf.

7.According to a 2018 study by Qwerty on digital growth in South Africa, 28.6 million people, or $52 \%$ of the South African population, use the Internet regularly. They do this mostly on their mobile phones (which comprises $78 \%$ of locally generated web traffic). Locals also spend a staggering $70 \%$ of their weekly activities on social media platforms alone: Facebook $(49 \%)$ is just ahead of YouTube $(47 \%)$, WhatsApp $(45 \%)$ and FB Messenger (31\%). The 18-24 and 25-34 age groups are the largest socia media groups, with a huge rise in the $45-65+$ group, probably because of their higher disposable income (cf. Joubert 2018).

8.Bauman (2011:8) describes liquid modernity as the currently existing shape of the modern condition described by other authors as 'postmodernity' 'late modernity', 'second' or 'hyper' modernity. What makes modernity 'liquid' and thus justifies the choice of name is its self-propelling, self-intensifying, compulsive and obsessive choice of name is its self-propelling, self-intensifying, compulsive and obsessive
'modernisation', as a result of which, like liquid, none of the consecutive forms of social life is able to maintain its shape for long. 
average of $3 \mathrm{~h} 14 \mathrm{~min} .{ }^{9}$ With a projected internet user penetration of $71.4 \%$ of the local population in $2020,{ }^{10}$ cyberspace has become the new social frontier. The 'reality' of digitalised, nomadic identities as well as cross-cultural contact, new forms of communication and technological innovation have had an unprecedented impact on most of the professions and social interaction. In this new reality, interactive digital-media experiences are providing unique interfaces between our biological selves and our digital selves, redefining our concepts of self and personality (cf. also Joubert 2018).

For the majority of South Africans, the days of unmediated, technology-free identity formation and social interactions are over. Reality now plays out on a continuum between virtual and real spaces. But it is not evenly distributed. In terms of Kuhn's model, it would appear that South Africa and the rest of the world find themselves on a continuum between a process of modification of existing approaches within the socalled Third Revolution, and the early formation of a new one. In the words of Nicholas Davis (2016): ${ }^{11}$

Indeed, in many parts of the world, aspects of the Second and Third Industrial Revolutions have yet to be experienced, complicated by the fact that new technologies are in some cases able to 'leapfrog' older ones. As the United Nations pointed out in 2013, more people in the world have access to a mobile phone than basic sanitation. In the same way, the Fourth Industrial Revolution is beginning to emerge at the same time that the third, digital revolution is spreading and maturing across countries and organizations. ${ }^{12}$ (n.p.)

\section{Christianity as change agent in a Fourth Industrial Revolution world?}

The church does not seem to be an official participant at most of the local and international public conventions and seminars where the $4 \mathrm{IR}$ is currently being discussed and facilitated. ${ }^{13}$ However, she does not need an official invitation to fulfil her calling and her prophetic function. The church needs to be keenly aware of the nature of new technologies and new conceptualisations of reality. The church can

9.See https://www.statista.com/statistics/484933/internet-user-reach-south-africa/.

10.See https://www.statista.com/statistics/484933/internet-user-reach-southafrica/.

11.See https://www.weforum.org/agenda/2016/01/what-is-the-fourth-industrialrevolution/.

12.Jeremy Rifkin, the American economic and social theorist, begs to differ. According to him, ' $[t]$ he Third Industrial Revolution - the digital revolution - has yet to reach
to to him, ' $[t]$ he Third Industrial Revolution - the digital revolution - has yet to reach
its vast potential, making it far too early to declare it over and done. It is possible that a new technology revolution, as powerful, expansive, and far-reaching in its impact on society as digitalization, will come along in the near or distant future, a which time we might affix the label "Fourth Industrial Revolution".'. Until then, we can safely maintain that the Fourth Industrial Revolution does not exist. https:// www.huffingtonpost.com/jeremy-rifkin/the-2016-world-economic-f_b_8975326. html.

13.To be fair, Schwab (https://berkleycenter.georgetown.edu/responses/welcomingfaith-in-the-fourth-industrial-revolution) does recognise the role of religion via the WEF's Global Agenda Council on the Role of Faith, which is developing a toolkit for leaders in government and business to facilitate a deeper understanding of the impact of religion on this new society. He states 'Religion, spiritual beliefs, and faith have the ability to explore new forms of modernity while staying connected to the nourishing effects of our traditional value systems'. Schwab's hope is that faith will 'catalyse' a new cultural renaissance that will enable people to be part of what he envisages as a global, connected civilisation. neither ignore nor escape the impact of globally adopted technologies on the development of personal and social identities as well as the formation of new understandings of reality.

Technology does not represent a different type of reality outside the parameters of the church; it has become an emergent reality principle in its own right, driving culture, church and society by 'ever proliferating digital innovations and, at the same time, providing compelling new ways of thinking about the digital reality which surrounds us' (Kroker \& Kroker 2013:13). Only when the church comes to terms with the staggering confluence of technological innovations across all spheres of reality in morally responsible and responsive ways, will she become conversant in the new immersive narratives of our day and will her voice also be heard. As Wilson (2008:26) correctly mentions, 'Our job as messengers of the gospel, is to speak in whatever language the culture is speaking'. Sweet (2019) puts it even more strongly:

It is apostasy not to be in one's own time, both for the disciple and the church. The ecclesiastical equivalent of sinning against the Holy Ghost is not to be open to the future ... Every time-andtechnology 'sign' opens up a biblical way forward and a 'sign of the Spirit'. A church that incarnates the timeless and the timely at the same time yields timefulness. (p. ix)

Religious communities are not called to hide out somewhere in 'safe' bunkers in efforts to safeguard themselves against disruptive technological transformations but to fill the moral vacuums created by the ever-increasing complexity and uncertainty associated with 4IR on all levels of society. Believers must be present in this never-ending drama of technological change, culture and human experience without losing their identity. They must be aware of the fact that risks are inherent to as well as unavoidable by-products of economic and technology development. They have to embrace the Zeitgeist [spirit of the times] and view it as the opportunity for the Heilige Geist [Holy Spirit] to guide and lead them to fulfil their responsibility to love and serve others and care for God's creation (cf. Sweet 2019:ix).

Only within the "... holy triangulation of being "in" the present culture, but not "of" the culture', as Sweet (2019:1) puts it, can the church have a positive, healing impact on this increasing science-fictional world. Only then can the church fulfil its prophetic function by also effectively warning against the dangerous ways in which technology can also dehumanise and entrap us in what Postman (1992) famously called 'the age of technopoly', one where technology becomes the only totalitarian perspective of life. To be an effective agent of change, the church has to use the timeless and timely 'weapons of mass-upbuilding' in its own arsenal in a world that is expected to change more in the next 20 years than in the previous 300 years. These include, among others, a fresh, immersive and 'embodied' understanding and performance of the Gospels as well as a rediscovery of the importance of being sages in a world that is fast turning into an interlocking array of technological systems and new advancements, 
which '... no longer require human involvement as anything but minions' (Gay 2018:10).

\section{The Bible as immersive text in an interactive Fourth Industrial Revolution world}

The Bible is definitely not out in the cold in this new era of ever-increasing technological changes with its emphasis on 'interactive, immersive experiences generated by computers and other technological interfaces' (Pimentel \& Texeira 1993:11). In fact, the prominence of mimesis and participation in both fictional and non-fictional worlds is evident in numerous new genres such as hypertext, electronic literature, video games, interactive drama and electronic installation art (cf. Jones \& Dawkins 2018:185) as well as in newer cognitive angles to narratives, which challenge the so-called disembodied approaches to texts.

Although the active participation of readers in the production of meaning in texts had always been a given, the pendulum has now swung from the earlier emphasis on form over content, and from decentred, emergent, multiple, unstable meanings towards more interactive experiences. At the same time, imagination inserts itself into reality with more vigour, with the emphasis on embodied perceptions and immersions in the worlds projected and/or described by narratives, in particular (cf. also Ryan 2015).

The virtualisation of texts, resulting from the marriage of electronic technology and narrative, nowadays produces anything from new kinds of historical information to endless fictional worlds. Within this enactment of 'narrative textuality as a virtual meeting place' (Tabby \& Wutz 1997:23), new experiences of sensory diversity are created as well as alternative embodiment and role playing through interaction with objects and inhabitants of such virtual worlds, whilst simultaneously also framing new narratives that could be enacted in everyday reality. No wonder the idea of immersion in narrative texts, or metalepsis as narratologists prefer to describe this idea of walking into a fictional story and becoming a character in it, is fast turning into more than a purely mental phenomenon or the product of an act of imagination on the part of readers.

The textual worlds created by the Gospels (as our biblical cases in point in this short study), with their distinctive connected sets of characters within specific habitable environments, possess an inherent immersive capacity that invites readers into their stories by means of emotional and ethical engagement. In their capacity as mimetic texts, the Gospels should, more than ever, facilitate experiences that assist people in imagining themselves being transported to (and contained in) the new liberating reality of Jesus. ${ }^{14}$ This requires that the reality presented in the Gospels (and in

14.This could be achieved, among others, by means of 'simulating in imagination the depicted scenes, characters, and events and spatializing the text by following the threads of various thematic webs' (Ryan 2015:33). other biblical texts) should be imaginatively proclaimed and presented as an immersive narrative domus, one that gives shape to a safe new habitat as well as to new forms of belonging, self-worth and actualisation.

\section{Performing the Gospels by way of an 'metanoetic' alignment with the mission of Jesus}

The Gospels are not merely aesthetic texts intended for recreational reading or entertainment. When read correctly, they invite their readers to become part of the kingdom of God as an alternative reality by means of 'metanoia' (Mk 1:15). Metanoia implies a radical change of identity when individuals are invited into a new life of followership in God's kingdom. Sadly, as Caputo (1999) remarks:

[W] e have chosen to translate this very beautiful word with 'I repent', which means 'I visit pain (poena) on myself again'.; 'I have a new heart' - that is the Christian translation, Jesus' tune, the dance, not the dirge. (pp. 206-207)

From this 'metanoetic' perspective, the church is called to embody the kingdom of God as a provocative, alternative reality that extends into our own time and space. ${ }^{15}$

Contemporary readers and hearers of the Gospels need to be steered towards becoming active participants in, and performers of the missio Christi, a mission that shapes us into people who know that we are deeply loved by God and, in turn, to love Him and others (cf. McKnight 2009). ${ }^{16}$ In an unpredictable 4IR world, where technology is developing faster than most people know how to make use of it; let alone how to reflect on its ethical application, people need to be drawn into the safe spaces of the Gospels by means of what Toolan (2016:39) in a different context describes as 'a process of emotionally-engaged sense-making'. This includes understanding, concern, judgement, engagement and ethical alignment with Jesus. At the same time, believers need to passionately perform the Gospels along the lines of a musical score (Rhoads \& Dewey 2014):

$[U]$ sing all the memory arts in the composition to get the melody in the head and on the heart so that it can be heard as a performance. What are the rhythms and the patterns? What does it sound like? What needs to be repeated in a variety of ways so that it does not get lost? Is it memorable for an audience? How do the patterns of structure and sound enable the performer to recall? How can the performer get the story into his or her body - through gestures, posture, movement, facial expressions so as to make the story memorable? What emotions does the

15.The difference between fiction and nonfiction "is not a matter of displaying the image of a world versus displaying this world itself, since both project a world image, but a matter of the function ascribed to the image. In one case, contemplating the textual world is an end in itself, while in the other, the textual world must be evaluated in terms of its accuracy with respect to an external reference world known to the reader through other channels of information' (Ryan 2015:64). However, as Pimentel and Texeira (1993:15) note, the first question is not whether a textual world 'is as real as the physical world but whether the created world is real enough for you to suspend your disbelief for a period of time'.

16.David Bosch (1993:10) prefers the term Missio Dei, which he defines as 'God's selfrevelation as the One who loves the world, God's involvement in and with the world, the nature and activity of God, which embraces both the church and the world, the nature and activity of God, which embraces both the church and the
world, and in which the church is privileged to participate. Missio Dei enunciates the good news in that God is a God-for-people'. 
performer want to arouse in the audience so that they do not forget their experience? How does all of this come together to lead the community to change and to act in a certain way? (p. 14)

As performers of the Gospels, the church, in particular, should echo the life-altering call of Jesus to love God unconditionally. It must also see others through the eyes of God, using the teachings of Jesus as its glasses, 'colored with His love for them' (Laubach, in McKnight 2009:100). This implies imitating Jesus in terms of his passion for the poor, the marginalised, the foreigners and the ostracised.

In a world where technology is fast turning into a dangerous master rather than a good servant, and where increasingly more people are forced to fit the requirements of soulless technologies, the rights and needs of 'embodied humans' must be emphasised more than ever. As part of the 'main performance' of the Gospels, human dignity in the presence of God and others must be emphasised in every possible context and situation where the impact of emerging technologies is on the table. Stakeholders and others have to be reminded constantly that the challenge of managing the potential harms that might result from the adoption of new technologies has to be weighed against the anticipated benefits for humanity in general, and specifically the poor, the homeless and the jobless. The call to a new metanoia must always be on the table if the church wants to be a relevant and reliable voice for those who 'were left behind' in this strangely alien 4IR world. The nature of this kind of 'metanoia' is captured eloquently by Martin Luther King Jr. in a speech delivered at the Southern Christian Leadership Conference in Atlanta on 16 August 1967 (quoted in Labberton 2010:23-24). In this instance, he offers an inspiring, contextually relevant performance of John 3:

Jesus realized something basic - that if a man will lie, he will steal. And if he will steal, he will kill. So instead of just getting bogged down in one thing, Jesus looked at him and said: 'Nicodemus, you must be born again'. He said, in other words, 'Your whole structure must be changed'. A nation that will keep people in slavery for 244 years will 'thingify' them make them new things. Therefore, they will exploit them, and poor people generally, economically ... And a nation that will exploit economically will have to have ... to use its military might to protect them. All of these problems are tied together. What I am saying today is that we must go from this convention and say, 'America, you must be born again!'

\section{Sages in a double-edged technological world}

The huge pace of technological development is a doubleedged sword. On the one hand (Prensky 2012):

$[T]$ echnology's evolution and rapid advance is tightly linked to mind and brain evolution, it is the symbiotic integration of technology with our minds that is producing 'brain gain' ... Today's technology is making this happen, and it is extending and 'liberating' our minds in many helpful ways. (pp. 1-2)
On the other hand, technological development with its 'promise' (threat?) of trans-human existence is becoming increasingly more at odds with human flourishing (Gay 2018:5). Foer (2017) even describes the rise of gigantic tech monopolies such as Apple, Google, Facebook and Amazon, with their efforts to complete the merger between man and machine, and the new understanding of human nature that they impose on us, as the creation of a world without mind:

Their devices and sites have collapsed privacy; they disrespect the value of authorship, with their hostility to intellectual property ... they hope to automate the choices that we make ... It is their algorithms that suggest the news we read, the goods we buy, the path we travel, the friends we invite into our circle. (p. 3ff.)

This new 'GRAIN world' (as an acronym for genetic engineering, robotics, artificial intelligence, information technology and nanotechnology; Sweet 2019:141) is fast dismantling one established institution after the other. Technology, coupled with a rise of artificial intelligence, has the potential to turn into the new religion of fact; the renowned economic advisor and author Leonhard $(2016,2020)$ is convinced that this 'religious' shift has already taken place:

Technology has replaced the once-mighty church and currently dominates our personal as well as professional lives. A few global behemoths - the churches of dataism - now control how we communicate and connect, search, buy and sell, entertain and learn. What was once used to connect us (so-called social media) is now dividing and manipulating us, catapulting us towards an algorithmic society. ${ }^{17}$ (n.p.)

There is an urgent need for sages who possess the necessary wisdom to traverse this unchartered terrain of technological innovation with insight and discernment. People everywhere are drowning in information and overwhelmed by technology, but they do not possess the necessary wisdom to survive, let alone thrive, in this 4IR world. Alvin Toffler's (1974:297) concept of 'future shock', which he described as 'the distress, both physical and psychological, that arises from an overload of the human organism's physical adaptive systems and its decision making processes', has turned into a daily reality for millions.

Although nothing could have prepared anyone for this technological onslaught, Christianity has a deep well of wisdom and knowledge at its disposal, one that is embedded in her sacred texts, liturgies, memories, perceptions and embodied experiences. This timeless reservoir of faith and wisdom, which has weathered the tests of time, has assisted believers throughout the ages to discern in timely fashion what it means to be truly human and how to flourish in the presence of God and others. For believers, discernment has always been essentially a faith-driven, relational and embodied process. 'Knowing God and knowing the world is to participate in the material, social and spiritual world by

17.See https://www.forbes.com/sites/cognitiveworld/2020/01/05/2020-will-bring-anew-renaissance-humanity-over-technology/\#5a765be1dd78. 
sharing with and relating to other participants' (Barentsen 2019:132). This kind of religious discernment always facilitates concrete expressions of faith, hope, integrity, respect and generosity in everyday life.

\section{The purpose of spiritual discernment in a Fourth Industrial Revolution reality}

The quantum era is upon us (cf. Hammack 2014), one in which artificial intelligence is invading every aspect of our lives. At the same time, the genomic era has also dawned (cf. eds. Das \& Dash 2019), one in which genetic engineering, genome-based medicine, life-patenting and DNA-editing are daily realities. They present us with endless possibilities of reshaping human beings and other species as well. At the same time, robotics, coupled with artificial intelligence, offers endless new opportunities from exploration to growth, to altogether losing our way in a world ruled by algorithms. We are literally faced with a new reality that could include anything from 'robo-doctors', to human brains fused with machines, to cyborgs, autonomous machines and weapons, to job automation, web-architected economies, endless forms of wearable technology, quantum computers, augmented reality and so on (Sweet 2019:139ff.).

People of faith need to read the signs of the times correctly. They should be able to discern wisely between right and wrong, yes and no and between the best possible courses of action that will facilitate the reshaping of societies from less human ones to ones where the value and dignity of all of humanity are ensured. As part of believers' 'risk assessment' of the nature and impact of technological change, the basic question should always be whether such change is driven by technology that is advantageous to human flourishing (and the enhancement of basic living conditions of impoverished individuals), or by politically unwise and/or socially insensitive handlings thereof by greedy corporations, institutions, groups and governments. In their role as agents of change, Christians should be able to comprehend when and where they should gratefully acknowledge the benefits of modern technology and celebrate it as an essentially healthy human enterprise, or one where people are allowing themselves and others to be diminished and de-humanised by their own technologies (Gay 2018:3).

New embodied expressions of biblical wisdom in a quantum world should not only replace dated theological constructs and obsolete ecclesiologies but also provide people with new formative lenses in their everyday lives through which they could view reality, interact with others, grow healthy relationships, manage day-to-day business and use technology in morally responsible ways. They should be taught to discern the merits of how any application of technology could assist them to more effectively serve their organisations and communities, and how it could assist others in reaching their full human potential as handworks of God.

It is the responsibility of the church, in particular, to constantly remind all stakeholders, when the 4IR is being discussed and implemented, that the type of society which should emerge from such new technological developments has to be a society of grace, restoration and inclusio. If not, the technological juggernaut of change 'in the form of genetic engineering, mood- and character-altering drugs, nanotechnology, and advanced forms of artificial intelligence' (Wallach 2015:5) will ultimately redesign our minds and bodies and redefine what it means to be human. In this instance, we should learn from Philip Pullman, one of the greatest storytellers of our day. As a devout atheist, he admits in an introduction to the Oxford World Classics edition of Milton's 'Paradise Lost' (as a retelling of the Genesis story, which he also inverted in his 'Dark Materials') that the story of Adam and Eve is 'the central story of our lives, the story that more than any other tells us what it means to be human'. To become more godly, we need to become more human, not post-human or trans-human. We cannot avoid the fact that we are entering an era in which technology will increasingly redefine who we are (Bergman 2016:2). However, the question is not simply what technology can do for us, but what we as change agents should allow technology to do.

\section{Acknowledgements Competing interests}

The author declares that he has no financial or personal relationships that may have inappropriately influenced him in writing this research article.

\section{Author's contribution}

S.J.J. is the sole author of this research article.

\section{Ethical considerations}

This article followed all ethical standards for research without direct contact with human or animal subjects.

\section{Funding information}

This research received no specific grant from any funding agency in the public, commercial or non-profit sectors.

\section{Data availability}

Data sharing is not applicable to this article as no new data were created or analysed in this study.

\section{Disclaimer}

The views and opinions expressed in this article are those of the author and do not necessarily reflect the official policy or position of any affiliated agency of the author. 


\section{References}

Bauman, Z., 2011, Culture in a liquid modern world, Polity, Cambridge.

Barentsen, J., 2019, 'Embodied realism as interpretive framework for spirituality, discernment and leadership', in J. Kok \& S.C. Van den Heuvel (eds.), Leading in a VUCA world: Integrating leadership, discernment and spirituality, pp. 119-138, Springer, Cham.

Bergman, N., 2016, Surviving the tech-storm: Strategy in times of technological uncertainty, Lid Publishing, London.

Bosch, D.J., 1993, Transforming mission: Paradigm shifts in theology of mission, Orbis Books, Maryknoll, NY.

Caputo, J.D., 1999, “"Metanoetics": Elements of a postmodern Christian philosophy', in F.J. Ambrosio (ed.), The question of Christian philosophy today, pp. 189-224, Fordham University Press, New York, NY.

Das, S. \& Dash, H.R. (eds.), 2019, Microbial diversity in the genomic era, Elsevier Academic Press, London.

Davis, N., 2016, 'What is the Fourth Industrial Revolution?', World Economic Forum viewed 05 May 2020, from https://www.weforum.org/agenda/2016/01/what-isthe-fourth-industrial-revolution/.

Foer, F., 2017, World without mind: Why Google, Amazon, Facebook and Apple threaten our future, Jonathan Cape, London.

Gay, C.M., 2018, Modern technology and the human future: A Christian appraisal, InterVarsity Press, Downers Grove, IL.

Hammack, D., 2014, Rethinking our story: Can we still be Christian in the quantum era?, Resource Publications, Eugene, OR.

Jones, S. \& Dawkins, S., 2018, 'The sensorama revisited: Evaluating the application of multi-sensory input on the sense of presence in the 360-degree immersive film in virtual reality', in T. Jung \& M. Claudia tom Dieck (eds.), Augmented reality and virtual reality: Empowering human place and business, pp. 183-198, Springer, Cham

Joubert, S., 2014, Echoes of charis: Paul's contextual reflections on salvation, Lit Verlag, Zürich.

Joubert, S., 2018, “"Flowing” under the radar in a multifaceted liquid reality: "The ekerk narrative"', HTS Teologiese Studies/Theological Studies 74(3), 4966. https:// doi.org/10.4102/hts.v74i3.4966

Kroker, A. \& Kroker, M., 2013, Critical digital studies: A reader, 2nd edn., University of Toronto Press, Toronto.
Kuhn, T.S., 1970, The structure of scientific revolutions, University of Chicago Press, Chicago, IL.

Labberton, M., 2010, The dangerous act of loving your neighbour: Seeing others through the eyes of Jesus, InterVarsity Press, Downers Grove, IL.

Leonhard, G., 2016, Technology vs. humanity: The coming clash between man and machine, The Futures Agency, Zurich.

Leonhard, G., 2020, '2020 Will Bring A New Renaissance: Humanity Over Technology', Forbes, viewed 06 May 2020, from forbes.com/sites/ cognitiveworld/2020/01/05/2020-will-bring-a-new-renaissance-humanity-overtechnology/\#39c95c47dd78.

McKnight, S., 2009, The Jesus creed: Loving God, loving others, 8th edn., Paraclete Press, Brewster, MA.

Pimentel, K. \& Texiera, K., 1993, Virtual reality: Through the new looking glass, McGraw Hill, London.

Postman, N., 1992, Technopoly: The surrender of culture to technology, Alfred A. Knopf Inc., New York, NY

Prensky, M., 2012, Brain gain: Technology and the quest for digital wisdom, MacMillan, New York, NY.

Rhoads, D. \& Dewey, J., 2014, 'Performance criticism: A paradigm shift in New Testament Studies', in K.R. Iverson (ed.), From text to performance: Narrative and performance criticisms in dialogue and debate, pp. 1-26, Cascade Books, Eugene, OR.

Ryan, M.-L., 2015, Narrative as virtual reality 2; Revisiting immersion and interactivity in literature and electronic media, Johns Hopkins University Press, Baltimore, MD.

Schwab, K., 2016, The Fourth Revolution, World Economic Forum, Geneva.

Schwab, K. \& Davis, N., 2018, Shaping the future of the Fourth Industrial Revolution, Penguin Random House, New York, NY.

Sweet, L., 2019, Rings of fire: Walking in faith through a volcanic future, NAV Press, Colorado Springs, CO.

Tabby, J. \& Wutz, M., 1997, 'Introduction', in J. Tabb \& M. Wutz (eds.), Reading matters: Narratives in the new media ecology, pp. 1-28, Cornell University Press, Ithaca, NY.

Toffler, A., 1974, Future shock, Pan Books, London.

Toolan, M., 2016, Making sense of a narrative text: Situation, repetition, and picturing in the reading of short stories, Routledge, London.

Wallach, W., 2015, A dangerous master: How to keep technology from slipping beyond our control, Basic Books, Philadelphia, PA.

Wilson, L., 2008, The wired church 2.0, Abingdon Press, Nashville, TN. 